\title{
Del Estado-sujeto a las categorías de ideología y alienación: reflexiones marxistas en torno al Ensayo histórico sobre la noción de Estado en Chile en los siglos XIX y XX, de Mario Cóngora ${ }^{1}$
}

From a State-subject to categories of ideology and alienation: Marxist reflections about Ensayo histórico sobre la noción de Estado en Chile en los siglos XIX y XX by Mario Góngora

Do Estado-sujeito às categorias de ideologia e alienação: reflexões marxistas em torno do Ensaio histórico sobre a noção de Estado no Chile nos séculos XIX e XX, de Mario Góngora

Dr. Daniel Fauré Polloni²

Recibido: 28 de abril de 2018 . Aceptado: 23 de mayo de 2018

\begin{abstract}
Resumen
El siguiente trabajo busca hacer un análisis crítico de la obra más reconocida del historiador chileno Mario Góngora: Ensayo histórico sobre la noción de Estado en Chile en los siglos XIX y XX, publicada en 1981. Se propone aquí un balance crítico a la luz de dos categorías centrales aportadas por el pensamiento de Marx: ideología y alienación.
\end{abstract}

Palabras clave: Mario Góngora - Estado - ideología - alienación - historiografía

\footnotetext{
1 El presente ensayo es parte de una investigación mayor, de carácter independiente, centrada en analizar el desarrollo historiográfico de la Nueva Historia Social en Chile desde 1970 hasta nuestros días.

2 Chileno. Licenciado en Historia (Universidad de Chile), Magíster en Historia de Chile (Universidad de Santiago de Chile) y Doctor en Historia de Chile (Universidad de Chile). Profesor adjunto del Departamento de Historia de la Universidad de Santiago de Chile. Contacto: daniel.faure@usach.cl

ORCID: https://orcid.org/0000-0003-3909-609X
} 


\begin{abstract}
The following work is aimed at making a critical analysis of the most recognized work by the Chilean historian Mario Góngora: Ensayo histórico sobre la noción de Estado en Chile en los siglos XIX y XX (Historical essay on the notion of State in Chile in the Nineteenth and Twentieth Centuries), published in 1981. It proposes a critical balance in light of two central categories contributed by the Marx thinking: ideology and alienation.
\end{abstract}

Keywords: Mario Góngora - State - ideology - alienation - historiography

\title{
Resumo
}

O seguinte trabalho busca fazer uma análise crítica da obra mais reconhecida do historiador chileno Mario Góngora: Ensaio histórico sobre a noção de Estado no Chile nos séculos XIX e XX, publicada em 1981. Propõe-se aqui um balanço crítico à luz de duas categorias centrais oferecidas pelo pensamento de Marx: ideologia e alienação.

Palavras-chave: Mario Góngora - Estado - ideologia - alienação - historiografia

\section{Introducción}

En el presente artículo proponemos una revisión crítica de la icónica obra del historiador chileno Mario Góngora titulada Ensayo histórico sobre la noción de Estado en Chile en los siglos XIX y XX -en adelante, el Ensayo-, que fuera publicada en nuestro país en 1981. ¿Por qué volver a la obra de Mario Góngora? Destaco dos motivos principales: el primero es que Góngora representa el punto más alto -en términos intelectualesde la corriente abierta por Alberto Edwards a comienzos del siglo XX denominada "historiografía conservadora" (Bastías 2004, Cristi y Ruiz 2015). Corriente que, aunque debilitada en los espacios académicos, sigue siendo hegemónica en el discurso de la clase política actual y en ese complejo constructo llamado "sentido común" u "opinión pública". El segundo motivo es que, en medio de una de las nuevas crisis del capitalismo (esta vez en su versión especulativa-financiera), cruzada por el nuevo auge de los movimientos conservadores nacionalistas, no han sido pocos los llamados a resucitar, reconstruir, revalorar, resignificar el Estado y, junto con ello, a reconfigurar su imagen de héroe salvador, en tanto base de la sociedad e instrumento de síntesis de los intereses 
y valores de una nación. Estas son razones suficientes para volver a la bravata gongoriana de 1981, con su famoso Ensayo, como el libelo más gravitante sobre el Estado producido en nuestra historia chilena reciente.

En las páginas siguientes proponemos la siguiente estructura: en primer lugar, una caracterización de la tesis central de la obra y del contexto en el que se produce, además de ofrecer un primer análisis que sitúe la propuesta gongoriana en una corriente -teórica y disciplinaria- más amplia: el pensamiento conservador. En segundo lugar, se analiza la impronta spengleriana y hegeliana en la noción de "Estado" que propone Góngora, para luego rastrear en la crítica marxiana al idealismo hegeliano elementos que puedan reactualizar el análisis de la obra del historiador chileno. En tercer y último lugar se propone una lectura crítica de la tesis de Góngora, analizándola a partir de las categorías marxianas de ideología y alienación.

\section{El hombre y su circunstancia}

Mario Góngora del Campo fue y sigue siendo uno de los historiadores más reconocidos de nuestro país. Personaje que, desde su reconocida socialmente trinchera intelectual -y quizás precisamente por esa condición librepensadora-, supo desfilar por diversos "ismos" en su trayectoria. Como plantea Gazmuri (2000): "un historiador profesional, riguroso, erudito e inteligente como pocos; quien luego de ser conservador, falangista y comunista, terminó integrista católico y lefebrista" (12). Así, existe cierta dificultad para calificarlo en torno a su obra puesto que, a pesar del peso que tiene el Ensayo, que lo lleva a alinearse en forma rápida con la corriente de pensamiento conservador, posee un espectro de producción historiográfica más amplio, que le permite pasearse por la historia política, económica, social, cultural y de las mentalidades. Por ello, compartimos la tesis de Bastías (2004) que reconoce dos etapas en la producción de Góngora: una primera -amplia y definida como una "historiografía académica" ${ }^{3}-y$ 
una tardía - de carácter conservador, donde se ubica el Ensayo. Estas etapas se mueven en el vaivén de sus dos grandes influencias: por un lado, la spengleriana, romántica e historicista (representada por Meinecke); y por otro, la influencia académica, en la que despliega su "moral científica", como la ha llamado Juan de Dios Vial Larraín (1987 67).

Sin embargo, el Ensayo es una producción contextual. Con esto queremos decir que responde más a la demanda de su tiempo que a una pregunta académica autorreferida: el historiador apoyó firmemente la Junta Militar por sacar al país de la "órbita de dominación soviética" (Góngora 1981 138) y alabó la Declaración de Principios que esta dictó en 1974, interpretándola como un documento conservador, de ideales tradicionalistas y nacionalistas (Cristi y Ruiz 147). Sin embargo, vio con estupor cómo la misma Junta -sobre todo a partir del arribo de los Chicago Boys y sus políticas neoliberales- traicionó este espíritu nacionalista, desarticulando con ello el aparato estatal y abriendo la puerta a prácticas de disolución del cuerpo social. Frente a esto, y siendo patente para el autor el peligro de la disolución tradicional, apeló a hacer una crítica, a partir de un "ensayo", en la que pudiera verse el peligro de este fenómeno en el largo plazo de nuestra historia republicana ${ }^{4}$. Así, bajo esta figura literaria, Góngora salió a defender

de la propiedad rural en el Valle del Puangue. Santiago: Editorial Universitaria, 1956; Mario Góngora. Origen de los inquilinos en el Valle Central. Santiago: Universidad de Chile, 1960, y Mario Góngora, Encomenderos y estancieros. Estudio acerca de la constitución social aristocrática de Chile después de la Conquista, 1580-1660. Santiago: Universidad de Chile, 1970.

4 Y el esfuerzo no fue en vano. A fin de cuentas, el texto causó revuelo más allá de los feudos universitarios -objetivo presente en la obra-, y, aunque criticado por algunos, reabrió una función social de la historiografía que parecía clausurada desde inicios de la Dictadura. Como comentara uno de sus detractores sólo dos años después: "rompe medio siglo de silencio social de los historiadores chilenos, saca por fin una voz históricamente sabia a plena luz del día, abre la ventana de la 'caverna Platónica' colonial, restaura la función social -más que académica- de los 'ensayos históricos' e incita el debate nacional a tomar verdadera altura, es decir, a retornar a lo que es propio. En este sentido, sin duda, este estudio está llamado a tener consecuencias de significación en la ya larga reflexión chilena sobre la 'crisis crónica' del país" (Salazar 1983 194). 
una decidida posición antineoliberal, tradicionalista y esencialista y, con ello, configuró un nuevo perfil en su trayectoria, delineado por su entronque con la escuela historiográfica conservadora.

En lo que respecta al análisis del Ensayo, comenzaremos mencionando que lo que plantea Mario Góngora no es una historia sobre la institución estatal, sino sobre la "noción de Estado". Esto no es una diferencia menor pues, como señala Álvaro Góngora (1990), lo medular de su análisis está en el Estado como símbolo, proceso en el que:

El Estado chileno fue perdiendo su valor simbólico fundamental. En el siglo pasado fue una vivencia efectiva en nuestra sociedad, poseía existencia real en el torrente vital del auténtico pueblo, al decir de nuestro historiador. El siglo XX fue conociendo paulatinamente el concepto de Estado, una teoría del Estado al amparo de fraseología doctrinaria, una abstracción articulada según principios, sin vida en la comunidad, finalmente sistemas, tendencias utópicas -nos dirá- o planificaciones (50).

En este sentido, lo atractivo de su planteamiento es que:

En rigor, lo que el autor se propuso fue "considerar o mirar" el largo tramo 1830-1980 en función de una cierta tendencia de larga duración -a saber, la "crisis de la idea de Estado en Chile"-, con respecto a la cual la década más crítica de nuestra historia [refiriéndose a la década del 70] toma sentido (Salazar 197).

Para Góngora (1981), el hilo conductor de la historia del Chile Republicano es esta "noción del Estado". Más aún, para el autor, el caso chileno muestra cómo es finalmente el Estado el agente que ha configurado a la nación chilena -y no al revés, idea que como un leit motiv atraviesa su obra. Para muestra dos botones gongorianos: "En Chile el Estado es la matriz de la nacionalidad: la nación no existiría sin el Estado" (Góngora 1981 5); o "la nacionalidad chilena ha sido formada por un Estado que ha antecedido a ella" (Id. 11). 
Sin embargo, para el autor, el desarrollo de este Estado estaría marcado por el sello de la decadencia. Sucesivamente -y en oleadaslas chilenas y chilenos hemos sido testigos de cómo dicha "noción de Estado" ha sido progresivamente carcomida por los regímenes liberales (1860-1890), a pesar del breve interludio generado en las postrimerías del siglo XIX, cuando el "ethos de la autoridad, [...] volvió a patentizarse con Santa María y con Balmaceda" (Góngora 1981 27-28). Y no sólo eso, sino que, posteriormente, desde Alessandri en adelante -y a pesar de encarnar éste un retorno a lógicas presidencialistas de mayor autoridad-, finalmente la lógica de la democracia para las masas o, como él la denominara, la "democracia caudillesca" (Id. 62), terminará de enviciar el ambiente y hacer entrar en crisis esta noción. En ese sentido, y para utilizar las palabras de Góngora, lo ocurrido en nuestra historia republicana desde 1920 en adelante, es consecuencia "natural en épocas desquiciadas por la necesidad de halagar a las masas" (Id. 83).

Finalmente, el triunfo de los conceptos liberales de democracia y Estado -en su lento proceso de corrosión y su cúmulo de planificaciones globales abstractas y alejadas de la realidad- podría haber visto un revés histórico importante posterior a 1973. Sin embargo, y en un ataque que parece final y catastrófico para Góngora, esta posibilidad se aleja al momento en que escribe sus líneas decantadas por el ingreso de los conceptos neoliberales, que significarían la mayor crisis de la noción de Estado vivida por el país. En ese sentido, el panorama descrito por Góngora al cerrar su análisis es desolador:

El espíritu del tiempo tiende en todo el mundo a proponer utopías (o sea, grandes planificaciones) y a modelar conforme a ellas el futuro. Se quiere partir de cero, sin hacerse cargo ni de la idiosincrasia de los pueblos ni de sus tradiciones nacionales o universales; la noción misma de tradición parece abolida por la utopía. En Chile la empresa parece tanto más fácil cuanto más frágil es la tradición. Se va produciendo una planetarialización o mundialización, cuyo resorte último es técnico-económico-masivo, no un alma. Suceden en Chile, durante este periodo, "acontecimientos" 
que el sentimiento histórico vivió como decisivos: así lo fue el 11 de septiembre de 1973, en que el país salió libre de la órbita de dominación soviética. Pero la civilización mundial de masas marcó muy pronto su sello. La política gira entre opciones marxistas a opciones neoliberales, entre las cuales existe en el fondo "la coincidencia de los opuestos", ya que ambas proceden de una misma raíz, el pensamiento revolucionario del siglo XVIII y de los comienzos del siglo XIX (Góngora 1981 138).

\section{Góngora: del pensamiento conservador al nacionalismo cultural}

Si bien el espectro disciplinario gongoriano fue amplio, el Ensayo lo vinculó firme y definitivamente con la corriente historiográfica conservadora. Esta corriente se ha destacado en Chile por la utilización de un corpus teórico basado en la dicotomía de un bien absoluto (la nación) y un mal absoluto (el comunismo internacional y su derivado, el enemigo interno), en la que la pervivencia del primero pasa por la necesaria extirpación, por cualquier medio, del segundo (Corvalán 153).

Sobre la base de esta concepción bipolar de la realidad -bien y mal absolutos-, Corvalán (1999) plantea la existencia de una serie de premisas que se desprenden de esta dicotomía, y que configuran una matriz particular de análisis por parte del pensamiento conservador, en la cual en cualquier realidad a estudiar: (a) existe un orden natural (expresado en la tradición); (b) ese orden implica, en el plano social, la existencia de jerarquías y, por ello, en el plano político, la existencia de aristocracias, y (c) su sustento social reside precisamente en esas creencias y tradiciones. Desde ahí se sustenta la oposición que ejerce el pensamiento conservador respecto del liberalismo, en tanto éste (d) cuestiona las premisas anteriormente dichas a partir de la razón abstracta, rompiendo el orden natural y (e), como resultado de este proceso macrohistórico, se experimenta el hundimiento de las culturas (con el hundimiento de los valores tradicionales). 
De allí surge la necesidad de la corriente conservadora de oponerse al ideario liberal, en tanto su avance implicaría, en el terreno político, (f) la división artificial por partidos, en general de intereses caudillistas, generando la demagogia y el alzamiento de las clases subalternas antes obedientes. Todo esto generaría un escenario perjudicial que conllevaría a que (g) el Estado pierda su misión trascendente, transformándose en botín de partitocracias corruptas, y donde (h) surgiría la democracia como un antivalor, iniciando con ello un proceso paralelo de disolución cultural (con el surgimiento del anarquismo, socialismo y comunismo). Una fase de descomposición que sólo se contrarresta con (i) un "decisionismo" caudillista necesario como salvación, con las FF.AA. como reserva última de la tradición y la nacionalidad (Corvalán 154-155).

Usamos la propuesta analítica de Corvalán porque sostenemos que el pensamiento gongoriano expresado en el Ensayo puede ser considerado icónico de esta corriente intelectual. Para ilustrarlo, repasaremos las premisas planteadas recurriendo para su ejemplificación a diferentes pasajes de la obra referida.

Sobre (a) el orden natural basado en la tradición, recordemos que el mismo Góngora se muestra escandalizado en el Ensayo al presenciar la corrupción interna del gobierno dictatorial al destruir este orden tradicional5; (b) orden generado por Portales, pero que es, por tradición, compartido con la aristocracia local, "a la americana". Es por ello que ve con pavor la ruptura de ese sustento, (c) expresado en el caso chileno con esta particular "noción de Estado" y que "en Chile parece tanto más fácil cuanto más frágil es la tradición" (Góngora 1981 138). En ese sentido, su oposición al liberalismo (d) es clara y reiterada, insistiendo en lo letal de su ingreso armado de "utopías"

5 De hecho, su crítica principal al gobierno militar en 1981 será que deja abierta la puerta utópica, cerrando, de paso, la tradicional: "El espíritu del tiempo tiende en todo el mundo a proponer utopías (o sea, grandes planificaciones) y a modelar conforme a ellas el futuro. Se quiere partir de cero, sin hacerse cargo ni de la idiosincrasia de los pueblos ni de sus tradiciones nacionales o universales; la noción misma de tradición parece abolida por la utopía" (Góngora 1981 138). 
y "planificaciones abstractas", sea esto en la forma que sea. A fin de cuentas, recordemos que, para Góngora, hablar de neoliberalismo o marxismo es casi una redundancia, en tanto que entre ambas opciones "existe en el fondo 'la coincidencia de los opuestos', ya que ambas proceden de una misma raíz, el pensamiento revolucionario del siglo XVIII y de los comienzos del siglo XIX" (Ibíd.).

Así, el desarrollo completo de nuestra historia republicana sería -para Góngora- una constante crisis que provocaría (e) el hundimiento de lo específicamente chileno -una noción de Estado que configuró la nación- ${ }^{6}$, trayendo como consecuencia la aparición de ( f y g) una serie de "democracias caudillistas" gavilladas por los "caprichos de la masa", en un proceso irreversible, donde "el ethos republicano [...] se extingue en 'las bases'" (Góngora 1981 125).

Por ello, no es de extrañar que el historiador muestre su rechazo a las lógicas representativas de la soberanía popular, y que se incline por apoyar regímenes autoritarios. (h) No olvidemos que el autor fue el mismo que vio en el golpe de Estado de 1973 la posibilidad de "reanudación de la idea de Estado Nacional" (133) y (i) en las FF.AA. "la columna vertebral del Estado chileno" (Góngora 1981 125).

Es así como el Ensayo constituyó la entrada, por la puerta ancha, de Góngora en el panteón conservador chileno, alcanzando con esta corriente su "madurez reflexiva" (Cristi y Ruiz 143), en una línea específica que José Bengoa (1982) definió como de "nacionalismo cultural" $(50)^{7}$.

6 Véase la siguiente cita que resume -nuevamente- la tesis central de su trabajo: "La idea cardinal del Chile Republicano es, históricamente considerado, que es el Estado el que ha ido configurando y afirmando la nacionalidad chilena a través de los siglos XIX y XX; y que la finalidad del Estado es el Bien Común en todas sus dimensiones: defensa nacional, justicia, educación, salud, fomento de la economía, protección a las actividades culturales, etc." (Góngora 1981 134).

7 Este autor define de la siguiente forma esta corriente de pensamiento: "Una corriente que podría describirse como nacionalista sin ser patriotera, un poco aristocrática en el sentido de creer que hay sectores 'destinados' a gobernar, y que tienen una cierta misión de cuidar el espíritu nacional. Es un sector culto, sin duda, esto es, que mira al pasado con nostalgia y ve con cierto horror la invasión de 'nuevos ricos', especula- 


\section{El concepto de Estado spengleriano-neohegeliano}

Posicionado Góngora en la línea de pensamiento conservador, se hace necesaria una revisión de un concepto fundamental en su trabajo: el Estado. Partamos señalando, en una lógica spengleriana clara, que Góngora trabaja con una "noción de Estado" y no un "concepto de Estado", y esto porque:

[...] el concepto es algo fijo, estático, en cambio la idea aprehende una realidad en todo su despliegue vital, en todos sus momentos. En este sentido, lo que él quiere marcar (Muller) es la idea del Estado como un todo en movimiento, no el concepto que puede definir cualquier código, "el Estado es la Nación organizada...", cosas así que estamos acostumbrados a ver en nuestros textos escolares (Góngora 1987 57-58).

Sin embargo, y si bien la mayoría de los que han estudiado la obra gongoriana han hecho el paralelo entre el chileno y el pensamiento de Oswald Spengler, su noción, aunque parte de la base de los postulados spenglerianos, exacerba su lógica organicista. Es decir, no es sólo que Góngora resuma su trabajo en la máxima de entender que: "Para mí, en el fondo, el Estado es una entidad espiritual, es lo que da forma a una nación" (Bulnes 4). Sino que, además, esta noción lentamente abandona su relación con un sujeto-pueblo para independizarse de él, transfigurándose él mismo en sujeto por sobre los grupos sociales.

Bien sabemos que Góngora concebía al Estado como algo más que un aparato administrativo. Como plantea Álvaro Góngora (1990) al revisar su obra:

[...] refiriéndose a la "República Socialista" bajo la dirección del periodista Carlos Dávila, destacó que su esfuerzo se ins-

dores, gentes de corbatas brillantes, y siúticos que los vienen a desplazar. Corrientes políticas más bien conservadoras, pragmáticas, y que no sirven de receptáculo fácil a modas utópicas que circulan por el mundo y llegan a las playas de estos subdesarrollados países" (Bengoa 50). 
piraba en la concepción de un Estado verdaderamente vivo y, en palabras del propio Dávila, que "tenga la tuición de la economía y las finanzas. Que sea un organismo vivo y no la concepción abstracta de un Fisco burócrata, complaciente y pagador. Que pueda exigir eficacia al individuo, porque le asegura a ese individuo la obligación social de darle trabajo". Mario Góngora asignó a estas expresiones máxima importancia: "tal vez por primera vez en Chile, muestran la concepción de Estado como un organismo viviente y no meramente como una abstracta entidad fiscal" (49, énfasis mío).

En ese sentido, coincidimos con Álvaro Góngora, pero hacemos notar el énfasis. En Mario Góngora la noción de Estado no sólo es una especie de corpus que da consistencia a la vida en sociedad, sino que en sí mismo, en tanto Estado, se transmuta en sujeto histórico, rector del desarrollo mismo de la historia de una nación ${ }^{8}$. Sostenemos que el pensamiento gongoriano va más allá de la visión spengleriana, en la que cierto estadio de desarrollo de una cultura -su capacidad expansiva- hace que logre una cohesión guerrera que denomina "Estado en forma". En el análisis del chileno, el Estado en sí mismo es el sujeto propio de la historia de

8 Véase la siguiente cita-resumen que Álvaro Góngora (1990) realiza sobre la obra de Mario Góngora: "En una mirada más global sobre su pensamiento, opinamos que concibió el Estado como un organismo que se va desplegando libremente, llegando a ser el resultado de una gran tradición. Es una idea vitalista-historicista del Estado, ajena a todo contractualismo. No era una mera entidad jurídica o mero Fisco, ni mera burocracia: lo entendió como una idea de totalidad, en la que el conjunto de los asuntos humanos se estrecha en una conexión íntima, en un todo vivo, y en el que Estado y pueblo están vinculados por una existencia acuñada en el acontecer de generaciones. El Estado en la concepción gongoriana es una entidad espiritual, un sujeto moral exigido por la finalidad del bien común, formador, "juez", defensor del territorio nacional y mediador de los conflictos sociales. Se distanciaba del burocratismo y del estatismo en lo contingente. Un Estado, para él, podía realizarse perfectamente entregando ciertos aspectos de sus tareas a los individuos e iniciativas privadas. Pero a lo que no debía renunciar es a regular las actividades particulares para someterlas a un interés superior general, ni tampoco debía renunciar a su rol en la tarea ineludible de configurar una nación orientada eludir la responsabilidad hacia ciertos valores. Y en nuestro siglo no debía eludir la responsabilidad especial de proteger a las capas miserables de la población" (Góngora 199072 énfasis mío). 
donde emana el orden y se generan naciones. Un Estado-sujeto o, como dijéramos en palabras del mismo Mario Góngora, "una entidad espiritual, [...] que da forma a una nación" (Bulnes 4).

De este modo, y si bien no por ello el pensamiento gongoriano destaca en originalidad, creemos necesario hacer esta pequeña distinción, en tanto este giro hace que las concepciones gongorianas se entronquen con otra línea de pensamiento más cercana a las concepciones hegelianas de Estado ${ }^{9}$. En ese sentido, no es necesario escarbar mucho para hallar una hebra fina de unión entre ambos planteamientos. No olvidemos que en la concepción hegeliana:

El Estado es la realidad de la idea ética (sittliche Idee), el espíritu ético en tanto que voluntad revelada, clara en sí misma, sustancial, que se piensa y se sabe y que cumple lo que ella sabe y en tanto que ella lo sabe. El Estado tiene su origen inmediato en la costumbre y su existencia mediatizada en la autoconciencia del individuo, en el saber y la actividad de éste, y el individuo por su convicción posee su libertad sustancial en el Estado, como su esencia, fin y producto de su actividad (Hegel 1960 257).

Así, podemos asemejar las concepciones de alma de Góngora y de espíritu de Hegel, de la misma forma en que se espejean las formas de concebir la tradición para el primero y la costumbre para el segundo. Con todo, el Estado hegeliano, entendido como la unificación de los intereses privados de los ciudadanos con un fin general, es para Hegel la condición organizativa racional para hablar de la existencia

\footnotetext{
9 Idea que el mismo Góngora podría confirmar. Como relata en una entrevista concedida a Simon Collier en 1983: "Mi primera gran "experiencia" en la filosofía de la historia -y eso ha de haber sido hacia 1935- fue la Decadencia de Occidente, de Spengler, en la traducción magnífica de García Morente. Sigo siendo un devoto de ese pensador tan vilipendiado, tan denostado y tan utilizado por la mayoría de los especialistas. Mi segunda y tercera lectura del libro fueron más críticas, lo que es comprensible pero no me hicieron admirarlo menos. En este campo especial he leído también, admirándolos, a Vico, Herder, varios románticos alemanes, Hegel (si bien sólo su Filosofía de la Historia)" (Collier 19).
} 
de un pueblo. Así, el Estado sería la manifestación de la idea universal (Hegel 1946 84) y, como realidad de la voluntad sustancial, sería el depositario de la historicidad, constituyéndolo en el sujeto de y en la realización de la Historia, frente al individuo cuyo deber máximo será el de ser miembro de dicho Estado ${ }^{10}$.

Es por ello que Hegel, como Góngora lo hará después, no puede sino alejarse de las concepciones liberales, en tanto el "sujeto Estado" no puede configurarse, en esta visión, como emanado de una serie confusa de voluntades individuales y contradictorias, sino en la estabilidad de su autolegitimación:

Rousseau preguntaba ¿cuál es el fundamento legítimo del Estado?... erige en principio de esa legitimidad la voluntad libre y contesta, sin fijarse para nada en el derecho positivo de los Estados... la voluntad general no debe considerarse como integrada por un conjunto de voluntades expresamente individuales. La voluntad general debe ser, por el contrario, la voluntad racional, aunque no se tenga la conciencia de ello. El Estado no es tampoco, por tanto, una de esas asociaciones concertadas por la arbitrariedad de los individuos (Hegel 1955 399-400).

Así, siguiendo esta línea de análisis, podemos coincidir con lo que plantea García de la Huerta (1987) en su revisión de la obra gongoriana. Este autor, al realizar su crítica al leit motiv del Ensayo, logra dar con una nueva hebra que nos permite hacer esta vinculación con el pensamiento hegeliano, precisamente a partir de uno de sus discípulos. Como planteara García de la Huerta -y abriendo la puerta a las críticas y contradicciones del pensamiento gongoriano-:

10 En palabras de Hegel: "El Estado, como realidad de la voluntad sustancial, realidad que él tiene en la autoconciencia particular elevada a su universalidad, es lo racional en y para sí. Esta unidad sustancial es el fin en sí absoluto e inmóvil, en el cual la libertad alcanza su derecho supremo, lo mismo que ese fin último posee el derecho más elevado frente al individuo cuyo deber máximo es ser miembro del Estado" (Hegel 1960 258). 
La fórmula "el Estado crea la Nación" es del filósofo neohegeliano Giovanni Gentile. Precisamente la recepción de Hegel en Italia está ligada a su gran problema político del siglo pasado: el de la independencia y unidad nacionales. La noción de Estado como totalidad y elemento de la unidad resulta entonces cardinal [...] Se mutila, en cambio, la idea de Gentile ('Se la nazione crea lo stato, lo stato crea la nazione') al pretender que "la nación no existiría sin el Estado". Lo cual resulta aberrante. ¿Quién crea y da forma, entonces, al Estado? (160).

Y es precisamente aquí donde toman mayor fuerza dichas contradicciones. Así, el Estado ya no es en sí mismo, como en Hegel, la encarnación de la idea, del "espíritu universal", sino, paradójicamente, es un "sujeto moral", un "organismo viviente", pero que ha sido generado por... otro hombre, menos espiritual, dudosamente moral: "En Gentile el Estado es, como la idea hegeliana, acto puro, fundamento del fundamento. La respuesta de Góngora -que no difiere de la de Edwards y Encina- es que la génesis radica en el 'genio de Portales'; pero Portales no es acto puro, lumen divino, encarnación del verbo" (García de la Huerta 160).

Por ello, García de la Huerta se atreve a plantear que, en el fondo, a esta concepción política -una posición conservadora y jerárquica de la sociedad- le hacía falta un fundamento. Y tal como la historiografía conservadora anterior cubrió sus postulados políticos por medio de la objetividad del discurso historiográfico, Góngora remata esta tendencia dándole base epistemológica a esta concepción de Estado:

Cuando Jaime Eyzaguirre advertía con razón la carencia del fundamento religioso en el Estado Portaliano, a diferencia de la monarquía hispánica, tal vez lo echaba de menos, pero olvidó señalar que la historiografía conservadora se ha encargado de reinventarlo a través de esta religión secularizada del Ejecutivo omnipotente. Sólo faltaba el fundamento filosófico de esta idea y Góngora lo intenta 
con este concepto del Estado causa sui, origen de sí mismo (García de la Huerta 163).

\section{Hacia un nuevo análisis del pensamiento gongoriano: un racconto hacia el pensamiento marxiano}

¿Qué nuevas entradas podemos realizar a la propuesta gongoriana? En las siguientes líneas sostenemos que una relectura de la crítica que realizó Marx -y Engels, de paso- al idealismo hegeliano y su concepción de la historia puede otorgar nuevas claridades en el análisis crítico de esta obra gravitante del historiador chileno, en tanto asumimos que la noción de Estado gongoriana -central en nuestro análisis- es tributaria de la propuesta hegeliana.

En particular, planteamos que las categorías de "alienación" e "ideología" propuestas por Marx y Engels -que se desprenden de la lectura crítica al idealismo hegeliano- pueden erigirse como poderosas herramientas para releer la noción de Estado propuesta en el Ensayo.

A riesgo de hacer una exposición sumaria, debemos comenzar señalando -como plantearan Bottomore y Rubel (1967)- que el pensamiento de Marx puede desglosarse en cuatro grandes categorías de análisis de los sistemas sociales: a) la estructura económica de la sociedad; b) la superestructura ideológica; c) la revolución social; d) el futuro de la sociedad (Cf. Bottomore y Rubel 38). En este escenario, nos interesa en particular profundizar en la segunda categoría marxiana, en tanto es desde la que podríamos dialogar con la noción de "Estado" de Góngora. En torno a dicha categoría, se daría para los autores citados:

[...] una contribución mucho más original [sobre todo en] el análisis de la superestructura ideológica y de su relación con lo que Marx llamó la base real de la sociedad [...] Su afirmación de que "no es la conciencia lo que determina al ser, sino el ser el que determina la conciencia" no es una proposición filosófica sino una proposición sobre la génesis de las construcciones ideológicas: el derecho, la política, la religión, el arte y la filosofía. Según Marx, estas "formas 
ideológicas" son el principal obstáculo para la investigación científica cuando se las considera por sí mismas, sin tener en cuenta las correlaciones que se pueden establecer entre un cierto estadio del desarrollo económico y los diversos productos culturales (Bottomore y Rubel 39).

En este contexto de análisis podemos inscribir las categorías marxianas de "alienación" e "ideología". Partamos de la base que el pensamiento de Marx tiene una deuda patente con el pensamiento hegeliano. Es a partir de su crítica que Marx -junto a Engels- buscará construir una lógica de estudio de la realidad en la que el punto de inicio sea "el proceso material de vida de los hombres":

En contraste directo con la filosofía alemana, que desciende del cielo a la tierra, nosotros ascendemos de la tierra al cielo. Es decir, para llegar a los hombres de carne y hueso no partimos de lo que los hombres dicen, imaginan o conciben, ni de lo que se ha dicho, pensado, imaginado o concebido de los hombres. Partimos de los hombres reales, activos y de su proceso real de vida y mostramos el desarrollo y los reflejos y ecos ideológicos de este proceso de vida. Los fantasmas del cerebro humano son sublimaciones necesarias del proceso material de vida de los hombres que puede definirse y fijarse empíricamente y está vinculado a premisas materiales. La moralidad, la religión, la metafísica y otras ideologías y sus formas de conciencia correspondientes pierden su apariencia de existencia autónoma. No tiene una historia ni un desarrollo propios; son los hombres los que al desarrollar su producción material y sus relaciones materiales modifican, junto con su existencia real, su pensamiento y los productos de su pensamiento. La vida no está determinada por la conciencia; la conciencia está determinada por la vida (Marx y Engels 1985 37).

Pero, ¿de dónde surge esta necesidad de cambiar el enfoque? Precisamente del predominio de las concepciones idealistas -con Hegel a la cabeza-; concepciones que las nuevas generaciones -los jóvenes 
hegelianos de izquierda- se veían incapaces de superar. Como la definen en La Sagrada Familia Marx y Engels (1971):

La concepción hegeliana de la historia presupone un espíritu abstracto o absoluto, que se desarrolla de tal manera que la humanidad se reduce a una masa que le sirve de soporte más o menos conscientemente. Hegel introduce en el marco de la historia empírica, exotérica, una historia especulativa, esotérica. La historia de la humanidad se convierte así en la historia del espíritu abstracto de la humanidad, un espíritu situado por encima y al margen del hombre real (103).

Sin embargo, a pesar de esta contraposición, hay un hilo conductor entre ambos, que es la categoría de alienación. Dicha categoría, central en el pensamiento hegeliano, es tomada por Marx y llevada al plano de lo real, más allá de las concepciones idealistas de Hegel. Con ello, los caminos se bifurcarían y sus dialécticas serán consideradas como contrarias. En palabras de Marx (1967):

Mi método dialéctico no sólo difiere fundamentalmente del de Hegel, sino que es su antítesis directa. Para Hegel, el proceso de pensamiento (que él transforma en un sujeto independiente, dotado de vida propia, al cual da el nombre de "idea") es el demiurgo de lo real; y para él lo real es la simple manifestación externa de la idea. Para mí, en cambio, lo ideal no es más que lo material transpuesto y traducido en el cerebro del hombre (22).

Pero, ¿de qué hablamos cuando hablamos de alienación? En términos generales, podríamos decir que:

[...] los seres humanos necesariamente producen un "poder objetivo" que es el conjunto de las relaciones de producción y de las fuerzas productivas existentes en una sociedad en un momento dado. Esta objetivación de la práctica humana no es en sí misma alienante. La alienación surge para Marx de la falta de control de los individuos sobre ese poder objetivo. Es sólo en estas circunstancias que las condicio- 
nes objetivas, que son prácticamente producidas, pueden gobernar a sus productores, en vez de ellos gobernar a sus productos (Larraín 48).

Sin embargo, dicho problema no lo era tanto para Hegel. A fin de cuentas, los círculos que se abren desde la idea pueden pasar y contaminarse del plano material de la existencia, pero finalmente, vuelven a su lógica ideal. Posición, por lo demás, contraria a las lógicas de Marx. Según sus propias palabras:

Hegel sólo concebía el trabajo en forma alienada, como actividad del espíritu puro. Para él, el proceso histórico era un movimiento y un conflicto de categorías abstractas, de las cuales los individuos reales no eran más que simples juguetes. La alienación política y económica, que Hegel comprendió y describió muy bien, era proyectada en el ciclo del pensamiento puro y el filósofo se situaba a sí mismo en la posición de testigo, de juez y de redentor del mundo alienado (Marx 1967 16).

Sin embargo, el problema no terminaba en Hegel, sino que se extendía más allá. A fin de cuentas, el desafío intelectual que enfrenta Marx en su época es una crítica que debe abarcar dos frentes de acción:

[...] cómo reconciliar el materialismo con el hecho de que la realidad no debería concebirse como un objeto dado que no incluye la actividad del sujeto; y cómo reconciliar el idealismo con el hecho de que el ser no puede ser reducido al pensamiento, mientras que el materialismo hace de la conciencia un reflejo de la realidad externa, el idealismo hace de la realidad un producto de la conciencia. El materialismo divide en dos mundos separados lo que Marx concibe como una unidad, mientras que el idealismo disuelve un mundo en el otro (Larraín 55).

En ese sentido, como plantea Larraín: "Marx quería afirmar su convicción de que la conciencia no es independiente de las condiciones materiales, contra el idealismo, y que la conciencia no es un reflejo pasivo de la realidad externa, contra el viejo materialismo" (Ibíd). 
Es aquí donde podemos hacer el nexo con la noción misma de "Estado". En su batalla contra las concepciones idealistas de Hegel, debía incluirse la idealización que éste hacía del Estado. Por lo mismo, su desafío fue llevar la categoría hegeliana al plano del análisis de los fenómenos sociales, de la base misma de la sociedad. Dicho de otra forma:

Frente a la divinización del Estado por Hegel, consideraba el Estado como otra forma de la alienación humana (como un poder arbitrario y externo que domina la sociedad) [...] Como en el caso de la alienación religiosa, Marx se preguntaba: ¿cuáles son las causas de estos fenómenos? ¿Por qué los seres humanos proyectan en los objetos exteriores, en las abstracciones deificadas, sus verdaderos poderes? ¿Por qué, por ejemplo, consideran el Estado como un poder que organiza la sociedad cuando es, en realidad, la estructura de la sociedad la que da origen al Estado? (Marx 1967 19).

Ahora, la clave estaría en que este proceso de alienación se relaciona con la inversión de la práctica social objetivada. Inversión que se percibe claramente en el plano de la religión o del Estado, al ver cómo las creaciones (Dios, Estado) se transforman en creadoras de los hombres y mujeres reales. Y frente a ello, y a pesar del mérito que Marx reconoce en Feuerbach en la dinámica de su desenmascaramiento, el problema no puede resolverse remitiéndolo al plano de la idea: es decir, no se puede aceptar que, para superar eso, baste la crítica filosófica, como plantea Feuerbach. Es por ello que Marx se verá en la obligación de denunciarlo, recalcando que dicha crítica no basta: para superar dicha división, se debe destruir la sociedad que genera dicha inversión -y no debatir a la idea misma- (Marx y Engels 2006 59).

Todo esto por algo simple: fue en un mundo determinado donde se crearon las condiciones para que alguien necesitara crear la religión. Por lo mismo, el camino de su superación no pasa por convencer a dicha sociedad de la farsa, sino por destruir el mundo que produjo esa necesidad de Dios -o, en nuestro caso, de un Estado-sujeto de la historia-. Es la sociedad la que produce a la religión como lectura 
invertida del mundo y, con ello, se perpetua la alienación, la pérdida del control del poder-hacer (la toma de decisiones sobre su propia creación).

El concepto de "ideología" se presenta articulado a la cuestión planteada. Para Marx, "[...] no es la alienación de la conciencia la que genera una realidad objetiva invertida, sino una realidad invertida la que genera una conciencia invertida" (Larraín 48). Por lo mismo, la conciencia de los individuos en situación de alienación se transformará en una falsa conciencia, y no sólo eso, el sistema de creencias producido por esta falsa conciencia dará pie a una segunda inversión: la ideología ${ }^{11}$.

Ahora, es necesario aclarar que:

El origen de esta inversión está en la realidad misma, que está de cabeza. Esto significa que Marx proponía la existencia de dos clases de inversiones: la inversión de la conciencia -ideología-y la inversión de la práctica social objetivada -alienación-. La ideología oculta la alienación, es una inversión de la inversión real (Larraín 49).

\section{Balance final: una vuelta a Góngora desde las categorías de Marx}

Al aplicar las categorías de Marx a una revisión crítica de la obra gongoriana, sostenemos que -parafraseando a Marx en su misma crítica a Hegel- el ejercicio de Góngora en su Ensayo no hace sino "subjetivizar el predicado"; es decir, traslada los atributos de los sujetos reales (los hombres y las mujeres) a sus creaciones -en este caso el Estado-.

Góngora, en su Ensayo, logra configurar una "noción de Estado" en la que éste se transforma en el sujeto mismo de la historia. Así, la

11 Es necesario aclarar que esta será nuestra base para el concepto de "ideología", independiente de que, como señala Bottomore \& Rubel (1967): "Más tarde, Marx utilizó el término ideología en otro sentido, por ejemplo, para designar un sistema de ideas deliberadamente equívoco y desorientador" (19). 
visión organicista gongoriana no hace sino asignar un papel activo a una creación humana -el Estado- transformándola en un sujeto suprahistórico, el cual en la esencia de su coherencia interna logra configurar un sentido a la historia chilena republicana y motivar con ello el despliegue de las acciones de los sujetos reales. Con ello, la propuesta de análisis gongoriana se ubica en las antípodas de la marxiana, la que: "Al revés de la concepción idealista de la historia, no debe buscar una categoría en cada período, sino que permanece siempre en el suelo real de la historia; no explica la práctica por la idea, sino que explica la formación de las ideas por la práctica material" (Marx y Engels 1985 27).

Así, si buscamos construir una interpretación de la historia del Chile Republicano tomando como eje de reflexión la figura del Estado y, a su vez, pretendemos integrar la premisa marxiana antes planteada, nos veríamos en la obligación de negar la tesis -central en la lectura gongoriana- de que sería el Estado quien crea a la Nación, en tanto su aceptación no sería más que la adopción y el despliegue -en clave historiográfica- de la ideología estatal. Bajo ese marco interpretativo, sostenemos que Góngora cae en la lógica, y estructura un poderoso ensayo, pero con pies de barro, en la que el Estado -y más específicamente la "idea del Estado"- logra ser configurador y reserva de sentidos, en batalla constante con sujetos de carne y hueso que, en su práctica objetiva, no harían más que corromperlo.

En ese sentido, si bien podríamos estar de acuerdo, como plantea Bengoa (1982), en que: "Chile nace como Estado antes que como Nación" (52), es necesario acotar simultáneamente que:

El triunfo de Santiago y la oligarquía centralista contra los grupos de provincia permite que muy tempranamente se constituya el Estado Nacional, válido para la mayor parte del territorio nacional [...] Se aniquilan militarmente las tendencias regionales y la llamada oligarquía terrateniente de Santiago -zona central- domina sin contrapeso el aparato estatal naciente. Pero, acto seguido, esta misma oligarquía comienza a cooptar a los líderes de las otras regiones, en especial a los líderes militares penquistas. Se aprende de 
inmediato la lección: que en política no se puede ganar diez a cero, que siempre hay que dejar espacio a los vencidos o de lo contrario éstos se rearmarán y pondrán sus lanzas nuevamente contra el vencedor (Bengoa 52).

Encontramos relevante la cita anterior en tanto presenta un giro epistemológico importante, que nos acerca más a las posturas del materialismo histórico marxista: desde esta perspectiva, el Estado se desacraliza, y se transforma en creación -ya no en creador- de los grupos sociales que construyeron su imagen y materializan sus intereses desde ella. Un aparato que es adornado, a su vez, por los temores, deseos y ambiciones de quienes lo crean y dirigen. En palabras de Marx y Engels (1985), habría que recordar que:

Los hombres son los productores de sus representaciones, de sus ideas, etc., pero los hombres son reales y actuantes, tal y como se hallan condicionados por un determinado desarrollo de sus fuerzas productivas y por el intercambio que a él corresponde, hasta llegar a sus formaciones más amplias. La conciencia no puede ser nunca otra cosa que el ser consciente, y el ser de los hombres es su proceso de vida real (Marx y Engels 26).

Dicho de otra forma:

[...] si un Estado es, en última instancia, una estructuración de poder sobre un territorio dado y en un tiempo determinado, ese Estado no es más que lo que grupos sociales concretos pudieron construir en términos de poder social, cualesquiera hayan sido sus "ideas puras" al respecto (Salazar 200).

Afirmamos que lo que plantea Góngora es un discurso historiográfico acrítico, en el que se despliega, con carácter objetivo, la ideología estatal (con todos sus ramajes legales y morales), que recubre una práctica social objetivada que se encuentra invertida. Y, con ello, vuelve a hacer el guiño idealista hegeliano al considerar la idea como la fuerza motriz de la historia. Tendencia que Marx y Engels supieron enfrentar $y$ advertir casi un siglo y medio antes: 
Si una época se cree determinada por motivos puramente "políticos" o "religiosos", aunque la "política" y la "religión" no sean más que las formas que sus motivos reales, el historiador acepta esta opinión. La idea, el "concepto" que aquellos hombres se hacen de su práctica real se transforma en la única fuerza activa y determinante que controla y determina la práctica de dichos hombres" (Marx y Engels 1985 29).

Ahora, con ello no sugerimos que el análisis de Góngora sea ingenuo. Colocado en una coyuntura compleja, en la que la reestructuración de las dinámicas de acumulación por parte de los grupos dominantes significó la reestructuración de sus aparatos de poder correspondientes, el autor quiso defender posiciones y, cual jugador de ajedrez, movió sus piezas hacia jugadas conocidas. En el fondo, afirmamos que su apuesta fue potenciar precisamente esa concepción de "Estado" -en la cual el mismo Góngora tendrá un lugar de peso, al menos intelectual-, atribuyéndole al mismo poderes suprahistóricos. Una apuesta enfocada en recubrir, bajo el discurso historiográfico conservador, una creación humana de articulación de poder -el Estado- como último recurso frente a nuevos grupos dominantes que lo veían como un estorbo en sus procesos de reestructuración.

En ese plano, Góngora sabe moverse con cautela y, frente al desmantelamiento encabezado por los Chicago Boys, pretende instalar la idea de que -parafraseando el cuento infantil- "el rey está vestido y el que proclame su desnudez coloca en peligro el futuro de la nación completa", en una lógica que el mismo Marx preveía en algunos sectores y grupos sociales: "Cuanto más poderoso es el Estado y, por consiguiente, cuanto más político es un país, menos probable es que busque la base de los males sociales y su explicación general en el principio mismo del Estado, es decir, en la estructura de la sociedad, de la que el Estado es expresión activa, consciente y oficial" (Marx 1967 236).

En ese sentido, si la respuesta gongoriana fue robusta pero contextual, buscando posicionarse en una coyuntura política compleja que tendía 
al cambio radical de paradigma, ¿hasta qué punto es pertinente en el escenario actual en que dicho paradigma político está afianzando y tiene carácter hegemónico? Creemos que, para analizar la evolución de los grupos sociales frente al aparato estatal hoy, la noción de Estado gongoriano ha perdido utilidad, en tanto: "El concepto de Estado aquí supuesto corresponde a un ente cerrado, lo más contrario a un sistema abierto sobre el entorno social e integrativo como ha sido la tendencia del Estado chileno, cuya estabilidad y continuidad en gran parte son atribuibles a dicha tendencia" (García de la Huerta 164).

Este es un problema que ya había sido advertido por otros autores, en tanto esta concepción de Estado como ente cerrado se presenta como insuficiente al momento de analizar el proceso mismo de su configuración y afianzamiento durante el siglo XIX. Como hace notar Salazar (1983):

Resulta inevitable pensar -conforme a esta lógica- que el "Estado portaliano" no admitía, dada su coherencia ideal, contradicciones internas que lo llevasen por sí a su desintegración. Ese régimen sólo podía caer por la inserción de elementos e influencias externas a él; pero esto resulta difícil de explicar cuando, por un camino u otro, se descubre que es la misma clase dominante chilena la que es a la vez portaliana y antiportaliana y la que concluye por destruir su Estado ideal, entre 1860 y 1891 (Salazar 197, énfasis mío).

Sin ir más lejos, tampoco nos resultará útil para explicar-sin modificar la lógica jerárquica- la ampliación natural de la misma clase dominante:

La interpretación de Góngora a la incorporación a la clase dominante de los Subercaseaux, Edwards, Matta y Gallos no puede ser más parcial. En vez de ver allí una ampliación compleja de la base de sustentación social del Estado -fruto de la mayor complejidad de la economía y sociedad chilena- ve una disminución de su poder, de su carácter y de "su alma" (Bengoa 53) 
Es por ello que, a lo sumo, podríamos coincidir en que el "Estado portaliano" -es decir, la creación de una figura estatal hecha por Portales según los intereses que su grupo manifestaba- "introdujo el principio de la legalidad, la idea de que es la investidura la que hace al mandatario, no el simple hecho de mandar, y que el poder legítimo radica en la nación no en personas o instituciones (García de la Huerta 155). Así, esa jugada histórica, hecha por hombres y mujeres reales -y pertenecientes a la élite nacional-, logró, en un plano cultural, generar un viraje en tanto que lograrían que "la búsqueda del Padre fue[ra] sustituida tempranamente por la búsqueda de la legitimidad. A los 'Padres de la Patria' que se encomiendan a la Virgen del Carmen, 'gran patrona de Chile', los suceden mandatarios electos que juran sobre la Constitución y la Ley" (Id. 156).

Ahora, ¿podría haber sido de otro modo? Creemos que no, si es que asumimos que han sido las élites las que han moldeado el Estado y sus discursos legitimadores, instalándolos como una memoria oficial. Sin embargo, no por ello debemos atribuirle categoría de natural a un orden social establecido por un sector social en desmedro de los otros, y menos negar la capacidad de otros grupos sociales de establecer un campo de disputa -material y simbólico- con esa creación. Eso es hacer política -elitista, por lo demás- recubierta de filosofía de la historia. Tal como hace Góngora con su diferenciación entre "pueblo" y "masa". En ese sentido, por ejemplo, se dirigen las críticas de Salazar (1983), al rebatir a Góngora cuando:

Habla de "instintos de masa", "caprichos de la masa", "masas que obedecen mientras la autoridad es poderosa"; conceptos que descansan más sobre una percepción puramente cuantitativa que sobre una de naturaleza histórico-social. De este modo, el autor concluye por negar a las "masas" la categoría de "pueblo", la que, en cambio, se reserva para aquél sector de la ciudadanía que demuestra tener sentido y conciencia del orden y la legitimidad del Estado (Salazar 199).

En ese sentido, y a manera de cierre y de hipótesis abierta a futuras consideraciones, creemos que Góngora no pudo rehuir de una tentación muy presente en algunas corrientes con respecto a la historia: 
aquella que intenta legitimar ciertas concepciones de mundo que se tiene en el presente a partir del acomodo de los hechos del pasado. Cuando ello ocurre, más que buscar interpretaciones que nos permitan comprender el pasado para así aprehender nuestro presente, se cae en la tentación de salvaguardar propuestas actuales ajustando lo que ha ocurrido en el pasado hasta constituirse en una justificación adhoc, de amoldar forzosamente los hechos en ciertos marcos teóricos o de juzgar a los sujetos históricos del pasado por no ser capaces de ver más allá del proceso histórico que vivenciaron -y que nosotros si podemos observar por el solo hecho de ser externos y extemporáneos a dicho proceso-. Ese juego es un paso fácil para olvidarnos de los sujetos reales y de sus circunstancias reales -pasadas y presentes- $y$ es puerta abierta para caer en juegos discursivos o idealistas. En ese sentido, a manera de balance, nos sumamos a la reflexión salazariana cuando señala que:

No es posible negar que el pasado tiene un rol determinante sobre el presente, en muchos aspectos significativos. Tampoco sería posible negar la sabiduría del proverbio árabe, citado por Bloch, que dice que "las nuevas generaciones se parecen más a su propio tiempo que a sus padres". Es un ejercicio difícil, sin duda, ponderar con objetividad el peso relativo y la influencia recíproca de las distintas etapas del proceso histórico. Es posible que en los países en desarrollo el pasado sea, o contenga, de algún modo, "el gran responsable". Pero sería un error grave hacer análisis de larga duración atribuyendo el conjunto de la "responsabilidad histórica" a la descomposición centenaria de una idea. El pasado pesa en la conciencia de los pueblos en desarrollo como una incógnita siempre abierta, pero ello no anula la historicidad de los intentos que se efectúan para escapar de él, ni pesa tampoco como mero pasado, ya que demasiado a menudo el pasado no es más que la retroproyección temporal de ciertas fuerzas acaso demasiado presentes. Aceptar la hegemonía determinante del pasado sobre los sucesivos presentes es una tentación perenne para los his- 
toriadores académicos, y el profesor Góngora, profesional por excelencia, no renuncia del todo a ella (Salazar 197).

\section{Bibliografía}

Bastías, Manuel. Historiografía, Hermenéutica Y Positivismo. Revisión de la historiografía chilena camino a la superación del positivismo. Santiago: Tesis de grado U. de Chile, 2004.

Bengoa, José. "Acerca de la noción de Estado en Chile: crítica al libro del profesor Mario Góngora", Revista Proposiciones 7 (1982): 45-58.

Bottomore, T. \& Rubel, M. "Introducción". En: Marx, Karl. Sociología y filosofía social, ed. T. Bottomore \& M. Rubel. Barcelona: Editorial Península, 1967.

Bulnes, María Angélica. "El espacio y el Estado, según el historiador Mario Góngora". La Segunda. 13 dic. 1982: 4.

Collier, Simon. "Una entrevista con Mario Góngora", The Hispanic American Historical Review 63-4 (1983): 663-675.

Corvalán Márquez, Luis. "La democracia como antivalor", Revista Mapocho 45 (1999): 153-160.

Cristi, Renato y Ruiz, Carlos. El pensamiento conservador en Chile. Santiago: Editorial Universitaria, 2015.

García de la Huerta, Marcos. "Nación-Estado y legitimidad en Chile. Reflexiones sobre un libro de Mario Góngora", Revista Opciones 8 (1987): 155-167.

Gazmuri, Cristián. "Historiografía conservadora chilena: la influencia de Oswald Spengler". El Mercurio. 12 nov. 2000: E 12.

Góngora, Mario. Civilización de masas y esperanza y otros ensayos. Santiago: Editorial Vivaria, 1987.

Góngora, Mario. Ensayo histórico sobre la noción de Estado en Chile en los siglos XIX y XX. Santiago: Editorial La Ciudad, 1981.

Góngora. Álvaro. "El Estado en Mario Góngora, una noción de contenido spengleriano", Revista Historia 25 (1990): 39-79.

Hegel, Georg. Filosofía del derecho, trad. A. Mendoza de Montero. Buenos Aires: Editorial Claridad, 1960.

Hegel, Georg. Lecciones sobre la Filosofía de la Historia Universal. trad. Gaos, 1928. Buenos Aires: Ediciones Revista de Occidente, 1946. 
Hegel, Georg. Lecciones sobre la historia de la filosofía I. México: Fondo de Cultura Económica, 1955.

Larraín, Jorge. El concepto de ideología Vol.1. Santiago: Editorial Lom, 2007.

Marx, Karl \& Engels, Frederich. La ideología alemana, Décimosexta ed. México: Ediciones de cultura popular, 1985.

Marx, Karl \& Engels, Frederich. La sagrada familia. O crítica de la crítica crítica. Buenos Aires: Editorial Claridad, 1971.

Marx, Karl \& Engels, Frederich. Ludwig Feuerbach y el fin de la filosofía clásica alemana (y otros escritos sobre Feuerbach). Traducción: Grupo de Traductores de la Fundación Federico Engels. Madrid: Fundación de Estudios Socialistas Federico Engels, 2006.

Marx, Karl. Sociología y filosofía social, ed. T. Bottomore \& M. Rubel. Barcelona: Editorial Península, 1967.

Salazar, Gabriel. "Historiadores, Historia, Estado y Sociedad. Comentarios críticos en torno al Ensayo histórico sobre la noción de Estado en Chile en los siglos XIX y XX, de Mario Góngora", Revista Nueva Historia 7 (1983): 193-200.

Vial, Juan de Dios. "Otra conversación más con Mario Góngora", Revista universitaria / Pontificia Universidad Católica de Chile 22 (1987): 65-67. 